\title{
Correction to: RIC in COVID-19—a Clinical Trial to Investigate Whether Remote Ischemic Conditioning (RIC) Can Prevent Deterioration to Critical Care in Patients with COVID-19
}

\author{
Sean M. Davidson ${ }^{1} \cdot$ Kishal Lukhna $^{2} \cdot$ Diana A. Gorog ${ }^{3} \cdot$ Alan D. Salama ${ }^{4}$ Alejandro Rosell Castillo ${ }^{5}$. Sara Giesz ${ }^{1}$. \\ Pelin Golforoush ${ }^{1}$. Siavash Beikoghli Kalkhoran ${ }^{1}$. Sandrine Lecour ${ }^{6}$. Aqeela Imamdin ${ }^{6}$. Helison R. P. do Carmo ${ }^{5}$. \\ Ticiane Gonçalez Bovi ${ }^{5} \cdot$ Mauricio W. Perroud Jr ${ }^{5} \cdot$ Mpiko Ntsekhe $^{2} \cdot$ Andrei C. Sposito $^{5} \cdot$ Derek M. Yellon $^{1}$
}

Published online: 7 July 2021

(c) Springer Science+Business Media, LLC, part of Springer Nature 2021

Correction to: Cardiovascular Drugs and Therapy https://doi.org/10.1007/s10557-021-07221-y

The original article has been corrected. Author "Dereks M. Yellon" should be "Derek M. Yellon."

The online version of the original article can be found at https://doi.org/10.1007/s10557-021-07221-y

Publisher's Note Springer Nature remains neutral with regard to jurisdictional claims in published maps and institutional affiliations.

Sean M. Davidson and Kishal Lukhna are joint first authors.

Mpiko Ntsekhe, Andrei C. Sposito, and Derek M. Yellon are joint senior authors.

The original article can be found online at https://doi.org/10.1007/ s10557-021-07221-y.

Derek M. Yellon

d.yellon@ucl.ac.uk

1 The Hatter Cardiovascular Institute, University College, London, 67 Chenies Mews, London WC1E 6HX, UK

2 Division of Cardiology, Groote Schuur Hospital and Faculty of Health Sciences, University of Cape Town, Cape Town, South Africa

3 Postgraduate Medicine, University of Hertfordshire, UK $\&$ East and North Hertfordshire NHS Trust, Stevenage, Hertfordshire, UK

4 Department of Renal Medicine, Royal Free Hospital, London, UK

5 Atherosclerosis and Vascular Biology Laboratory, State University of Campinas, Campinas, Brazil

6 The Hatter Institute for Cardiovascular Research, University of Cape Town, Cape Town, South Africa 